\title{
Demethylzeylasteral (T-96) initiates extrinsic apoptosis against prostate cancer cells by inducing ROS-mediated ER stress and suppressing autophagic flux
}

Dong-lin Yang ${ }^{1,2^{*}+} \mathbb{B}$, Ya-jun Zhang ${ }^{1+}$, Liu-jun He ${ }^{1}$, Chun-sheng Hu' ${ }^{1}$, Li-xia Gao ${ }^{1}$, Jiu-hong Huang ${ }^{1,2}$, Yan Tang ${ }^{1}$, Jie Luo ${ }^{1}$, Dian-yong Tang ${ }^{1 *}$ and Zhong-zhu Chen ${ }^{1 *}$

\begin{abstract}
Background: Demethylzeylasteral (T-96) is a pharmacologically active triterpenoid monomer extracted from Tripterygium wilfordii Hook F (TWHF) that has been reported to exhibit anti-neoplastic effects against several types of cancer cells. However, the potential anti-tumour effects of T-96 against human Prostate cancer (CaP) cells and the possible underlying mechanisms have not been well studied.

Results: In the current study, T-96 exerted significant cytotoxicity to CaP cells in vitro and induced cell cycle arrest at S-phase in a dose-dependent manner. Mechanistically, T-96 promoted the initiation of autophagy but inhibited autophagic flux by inducing ROS-mediated endoplasmic reticulum (ER) stress which subsequently activated the extrinsic apoptosis pathway in CaP cells. These findings implied that T-96-induced ER stress activated the caspasedependent apoptosis pathway to inhibit proliferation of CaP cells. Moreover, we observed that T-96 enhances the sensitivity of $\mathrm{CaP}$ cells to the chemotherapeutic drug, cisplatin.
\end{abstract}

Conclusions: Taken together, our data demonstrated that T-96 is a novel modulator of ER stress and autophagy, and has potential therapeutic applications against CaP in the clinic.

Keywords: T-96, CaP, ER stress, Apoptosis, Autophagic flux, Cisplatin

\section{Background}

Prostate cancer $(\mathrm{CaP})$ is one of the cancers associated with high incidence and mortality rates among men worldwide [1]. Increasing evidence from studies show that the development of $\mathrm{CaP}$ is associated with perturbations in the androgen receptor (AR) signalling

\footnotetext{
*Correspondence: dlyang@cwu.edu.cn; tangdy2008@163.com; 18883138277@163.com

†Dong-linYang and Ya-jun Zhang contributed equally to this work ${ }^{1}$ College of Pharmacy, National \& Local Joint Engineering Research Center of Targeted and Innovative Therapeutics, Chongqing Key Laboratory of Kinase Modulators as Innovative Medicine, Chongqing University of Arts and Sciences, Chongqing 402160, China

Full list of author information is available at the end of the article
}

pathway $[2,3]$. AR is a ligand-dependent transcription factor belonging to the nuclear receptor family. Currently, androgen deprivation is the main treatment strategy for early stage of $\mathrm{CaP}$ since initial $\mathrm{CaP}$ cell proliferation is dependent on androgens. However, there is no effective therapy against castration-resistant $\mathrm{CaP}$, a lethal form of $\mathrm{CaP}$ that is androgen-independenct [4]. Despite the great advances in the therapeutic strategies against $\mathrm{CaP}$, there are increased incidences of recurrence and metastasis of $\mathrm{CaP}$ [5]. Thus, there is need to identify novel agents that are effective in suppressing the development and progression of $\mathrm{CaP}$ with minimal side effects, to improve survival rates among $\mathrm{CaP}$ patients. original author(s) and the source, provide a link to the Creative Commons licence, and indicate if changes were made. The images or other third party material in this article are included in the article's Creative Commons licence, unless indicated otherwise in a credit line to the material. If material is not included in the article's Creative Commons licence and your intended use is not permitted by statutory regulation or exceeds the permitted use, you will need to obtain permission directly from the copyright holder. To view a copy of this licence, visit http://creativecommons.org/licenses/by/4.0/. The Creative Commons Public Domain Dedication waiver (http://creativecommons.org/publicdomain/zero/1.0/) applies to the data made available in this article, unless otherwise stated in a credit line to the data. 
The endoplasmic reticulum (ER) is the largest intracellular organelle and it plays a vital role in the synthesis, modification, assembly, folding and structural maturation of proteins [6]. When the ER protein-folding capability is exceeded, unfolded or misfolded proteins accumulate in the ER lumen and can lead to the occurrence of ER stress $[7,8]$. Cells have evolved a highly protective signal transduction pathway, referred to as unfolded protein response (UPR), to alleviate ER stress by enhancing protein folding ability, reducing protein transduction rate and degrading unfolded and misfolded proteins $[9,10]$. ER stress can promote UPR-induced autophagy in damaged cells, which causes autophagic vesicles to engulf the impaired ER. The UPR signal is mainly initiated through the activation of three transmembrane proteins located on ER: inositol-requiring enzyme $1 \alpha$ (IRE $1 \alpha)$, double-stranded RNA-dependent protein kinase (PKR)-like endoplasmic reticulum kinase (PERK) and activating transcription factor 6 (ATF6) $[11,12]$. Initiation of the UPR pathway is a mechanism by the stressed cells to accommodate and survive the ER stress through transcriptional and translational reprogramming [13]. However, if protein folding homeostasis cannot be restored in the ER, UPR initiates an alternative signalling pathway, termed terminal UPR, which eventually promotes apoptosis induced by the toxicity of unfolded/misfolded proteins $[9,10,14]$. Therefore, the induction of ER stress above a critical threshold by novel compounds and the subsequent activation of the programmed cell death signalling pathway may be an effective strategy for cancer therapy.

Tripterygium wilfordii Hook F (TWHF), commonly known as "lei gong teng" or "thunder god vine", has been reported to treat a wide range of autoimmune and inflammatory diseases such as rheumatoid arthritis, ankylosing spondylitis, systemic lupus erythematosus and psoriasis [15-18]. The major effector components of TWHF are triptolide and celastrol, which are diterpenoid and triterpenoid compounds, respectively. Triptolide and celastrol have been shown to have anti-tumour activities by inducing apoptotic or autophagic cell death as well as cell cycle arrest in a series of cancer cells [17-22]. Demethylzeylasteral (T-96), a triterpenoid monomer compound, is a component of TWHF that is associated with considerably lower toxicity effects compared to triptonide, celastrol and triptolide in in vitro and in vivo studies [23]. Previous studies have indicated that T-96 is capable of suppressing cell proliferation, metastasis and angiogenesis, as well as promoting cell apoptosis in various malignant carcinomas, such as melanoma [24], glioblastoma [25] and breast cancer [26]. Interestingly, T-96 is also involved in the inhibition of pancreatic cancer proliferation through autophagy-induced apoptosis, and significantly increases chemosensitivity to gemcitabine [27].
However, there have been no reports on the regulatory mechanisms underlying the anti-tumour effects of T-96 in human CaP.

In the present study, we evaluated the anti-tumour effects of T-96 against $\mathrm{CaP}$ and the underlying mechanisms involved in the inhibition of $\mathrm{CaP}$ cell growth. We further investigated whether T-96 increases the chemo-sensitivity of $\mathrm{CaP}$ cells to cisplatin. Our results demonstrated for the first time that T-96 inhibited cell proliferation through cell cycle arrest, initiating autophagy and inducing ER stress-mediated apoptotic cell death.

\section{Materials and methods \\ Reagents and antibodies}

Demethylzeylasteral (T-96, molecular formula: C29H36O6, molecular weight: 480, T3418), Z-VADFMK (T6013), Rapamycin (T1537), Chloroquine (T8689) and Cisplatin (T1564) were purchased from TOPSCIENCE (Shanghai, China). Penicillin-Streptomycin, 3-(4,5-Dimethylthiazol-2-yl)-2,5-diphenyltetrazolium bromide (MTT), and propidium iodide (PI) were purchased from Sigma-Aldrich (MO, USA). Cell culture medium including DMEM (SH30022.01B) and F12K (SH30526.01) were sourced from HyClone (Logan, USA) while fetal bovine serum (FBS) was purchased from Natocor (Cordoba, Argentina). All the primary antibodies were bought from Cell Signaling Technology (MA, USA), while the secondary antibodies were purchased from LI-COR Biosciences (NE, USA).

\section{Cell culture}

Human CaP cell lines DU145 and PC3, and normal adult prostatic epithelial cell line PNT1A were obtained from the American Type Culture Collection (ATCC, VA, USA). All cell lines were mycoplasma-free and were authenticated using STR profiling. DU145, PC3 and PNT1A cells were cultured in Dulbecco's modified Eagle's medium (DMEM)/High glucose culture medium, Kaighn's modification of Ham's F-12 medium and Roswell Park Memorial Institute (RPMI) 1640 medium, respectively, supplemented with $10 \%$ fetal bovine serum, $1 \%$ Penicillin-Streptomycin at $37^{\circ} \mathrm{C}$ in a humidified incubator containing $5 \% \mathrm{CO}_{2}$.

\section{Cell viability assay}

DU145, PC3 and PNT1A cells were plated into 96-well plates (3000 cells/well) and incubated at $37{ }^{\circ} \mathrm{C}$ with various concentrations of T-96, cisplatin, and T96 combined with cisplatin for designated durations. Thereafter, $1 \%$ MTT was added $(20 \mu \mathrm{L} /$ well $)$ and incubated at $37^{\circ} \mathrm{C}$ for $4 \mathrm{~h}$ followed by dissolution of the crystals using DMSO. Absorbance was then detected at $570 \mathrm{~nm}$ using 
a microplate reader (Bio-Tek, VT, USA), and analyzed using GraphPad Prism 7.0. All experiments were performed in triplicates.

\section{Colony formation assay}

DU145 and PC3 cells were plated into six-well plates (500 cells/well) and cultured for 7 days under different treatment conditions. The colonies formed were washed twice with Phosphate Buffered Saline, fixed with 4\% Paraformaldehyde for $15 \mathrm{~min}$ at room temperature and then stained with $1 \%$ crystal violet for $30 \mathrm{~min}$. All statistical measurements were performed in triplicates.

\section{5-Ethynyl-20-deoxyuridine (EdU) incorporation assay}

The proliferation rate of human $\mathrm{CaP}$ cells was investigated using BeyoClick ${ }^{\mathrm{TM}}$ EdU Cell Proliferation Kit with Alexa Fluor 555 (C0075S, Beyotime, Shanghai, China) according to the manufacturer's protocols. Briefly, DU145 and PC3 cells at the logarithmic growth stage were seeded into 24-well plates prior to treatment with different concentrations of T-96 for $48 \mathrm{~h}$. Thereafter, the cells were incubated with $10 \mu \mathrm{M}$ EdU working solution in the dark room for $2 \mathrm{~h}$ at $37{ }^{\circ} \mathrm{C}$. The labeled cells were then fixed with $4 \%$ Paraformaldehyde for $20 \mathrm{~min}$, permeabilized with $0.1 \%$ Triton-X100 for $10 \mathrm{~min}$, and then stained with click reaction solution in the dark for $30 \mathrm{~min}$. The cells were also incubated with $1 \mathrm{mg} / \mathrm{mL}$ 2-(4-amidinophenyl)-6-indolecarbamidine dihydrochloride for $30 \mathrm{~min}$. The images were captured using a fluorescence microscope (Olympus, Tokyo, Japan) and the percentage of EdU-positive cells was calculated using GraphPad Prism 7.0.

\section{Flow cytometry analysis}

The flow cytometry analysis was performed as previously described [28]. Briefly, PI/RNase staining buffer [Becton Dickinson (BD)] was used to assess the cell cycle progression, while AnnexinV-fluoresceine isothiocyanate/ PI apoptosis assay kit (C1062S, Beyotime, China) was used to assess apoptosis, according to the manufacturer's guidelines. Finally, the stained cells were analyzed using BD AccuriTM C6 flow cytometry (BD Biosciences, USA) and FlowJo 7.6 software.

\section{Western blot analysis}

The western blot assay was conducted as previously reported [29]. In brief, whole-cell lysates were obtained by suspending cells in RIPA buffer (P0013B, Beyotime, Shanghai, China), followed by protein quantification using a BCA (Bicinchoninic Acid) Protein Assay Kit (P0010S, Beyotime, Shanghai, China). Immunoreactivity was visualized by an odyssey two-color infrared fluorescence imaging system (LI-COR Biosciences, NE, USA). $\beta$-Tubulin was used as the loading control.

\section{Determination of reactive oxygen species (ROS) formation} Intracellular ROS levels were measured using a ROS Assay Kit (S0033S, Beyotime, Shanghai, China) according to the manufacturer's protocols. CaP cells treated with T-96 or the control were incubated with serum-free DMEM or F12K containing 2,7-dichlorodi-hydrofluorescein diacetate (DCFH-DA, $10 \mu \mathrm{M})$ for $20 \mathrm{~min}$. Subsequently, cell suspensions were centrifuged and washed three times with serum-free DMEM, and then visualized using a fluorescence microscope (IX53/DP80, Olympus Corporation, Japan).

\section{$\mathrm{Ca}^{2+}$ signals measurement}

Intracellular $\mathrm{Ca}^{2+}$ signaling was determined using Fluo-4 AM (S1060, Beyotime, Shanghai, China) according to the manufacturers' protocols. CaP cells were collected and washed three times with PBS, and then incubated with 1 $\mu \mathrm{M}$ Fluo-4 AM in PBS for $30 \mathrm{~min}$ at $37^{\circ} \mathrm{C}$. Cells loaded with Fluo-4 AM were then washed with PBS and incubated for an additional 20 min to ensure that Fluo-4 AM was completely transformed into Fluo-4. Intensity of fluorescence was captured using a fluorescence microscope (IX53/DP80, Olympus Corporation, Japan).

\section{Autophagy analysis}

Autophagy analysis was performed as described previously [30]. In brief, the lentivirus packaging vectors (Pspax2, pMD2G) and GFP-LC3B/mCherry-GFP-LC3B were co-transfected into HEK293T cells using the Lipo8000 transfection reagent (C0533, Beyotime, Shanghai, China). Viral particles were collected $48 \mathrm{~h}$ after transfection and then used to infect CaP cells using Polybrene $(10 \mu \mathrm{g} / \mathrm{mL})$. Subsequently, cells were screened using puromycin $(10 \mu \mathrm{g} / \mathrm{mL})$ to obtain cells with stable expression of GFP-LC3B or mcherry-EGFP-LC3B. The transgenic cells were then treated using different concentrations of T-96, and analyzed using the high content analysis system-operetta CLS ${ }^{\mathrm{TM}}$ (PerkinElmer, Waltham, MA, USA).

\section{Statistical analysis}

All experiments were performed in triplicates. GraphPad Prism version 7.0 (GraphPad Software, San Diego, CA, USA) was used for statistical analysis. Data were presented as mean \pm Standard deviation, and the ANOVA method was used to compare differences between groups. $\mathrm{P}<0.05$ was considered to be significant. 


\section{Results}

\section{T-96 exhibits cytotoxic effects against CaP cells}

The chemical structure of T-96 is shown in Additional file 1: Figure S1A. Since T-96 suppresses the growth of various cancer cells, we investigated if it has anti-cancer effects against $\mathrm{CaP}$ cell lines such as DU145 and PC3. We found that T-96 significantly inhibits cell proliferation in a dose- and time-dependent manner (Additional file 1: Figure S1B). The half maximal inhibitory concentration $\left(\mathrm{IC}_{50}\right)$ values of T-96 in DU145 and PC3 were 11.47 $\mu \mathrm{M}$ and $13.10 \mu \mathrm{M}$, respectively (Additional file 1: Figure $\mathrm{S} 1 \mathrm{C})$. In contrast, exposure to T-96 was associated with minimal cytotoxicity in normal adult prostatic epithelial cell line PNT1A (Additional file 1: Figure S1D). Cisplatin, an antineoplastic chemotherapeutic agent, was used as a positive control to treat $\mathrm{CaP}$ cells with the $\mathrm{IC}_{50}$ values in DU145 and PC3 being 6.95 $\mu \mathrm{M}$ and $13.03 \mu \mathrm{M}$, respectively (Additional file 1: Figure S1E). Additionally, we found that DU145 and PC3 cell numbers were negatively correlated with the concentration of T-96 used (Fig. 1A). We further conducted colony formation and 5-ethynyl2 -deoxyuridine (EdU) assays to evaluate the inhibitory effect of T-96 on cell growth and proliferation of $\mathrm{CaP}$ cells. As shown in Fig. 1B, exposure to T-96 reduced the size and number of $\mathrm{CaP}$ cell colonies in a dose-dependent manner. Similarly, results of EdU-staining indicated that exposure to T-96 significantly deceased DNA synthesis in a dose-dependent manner, implying that T-96 inhibits the growth and survival of $\mathrm{CaP}$ cells (Fig. 2A).

\section{T-96 inhibited cell cycle progression by arresting CaP cells in the S-phase}

Cell cycle analysis was conducted to determine the mechanism underlying the anti-proliferative effects of T-96 in CaP cells. Results of flow cytometry, showed that T-96 significantly induced cell cycle arrest at S-phase by decreasing the distribution of DU145 and PC3 cells in G0/G1 phase (Fig. 2B). Since T-96 had induced cell cycle arrest of DU145 and PC3 cells in the S phase, we analyzed its effect on the expression levels of S-phase related proteins to determine if T-96 induced cell cycle arrest through modulation of protein expression. Results of western blot analysis showed that T-96 significantly decreased the levels of Cyclin A, Cyclin B, CDK1 and
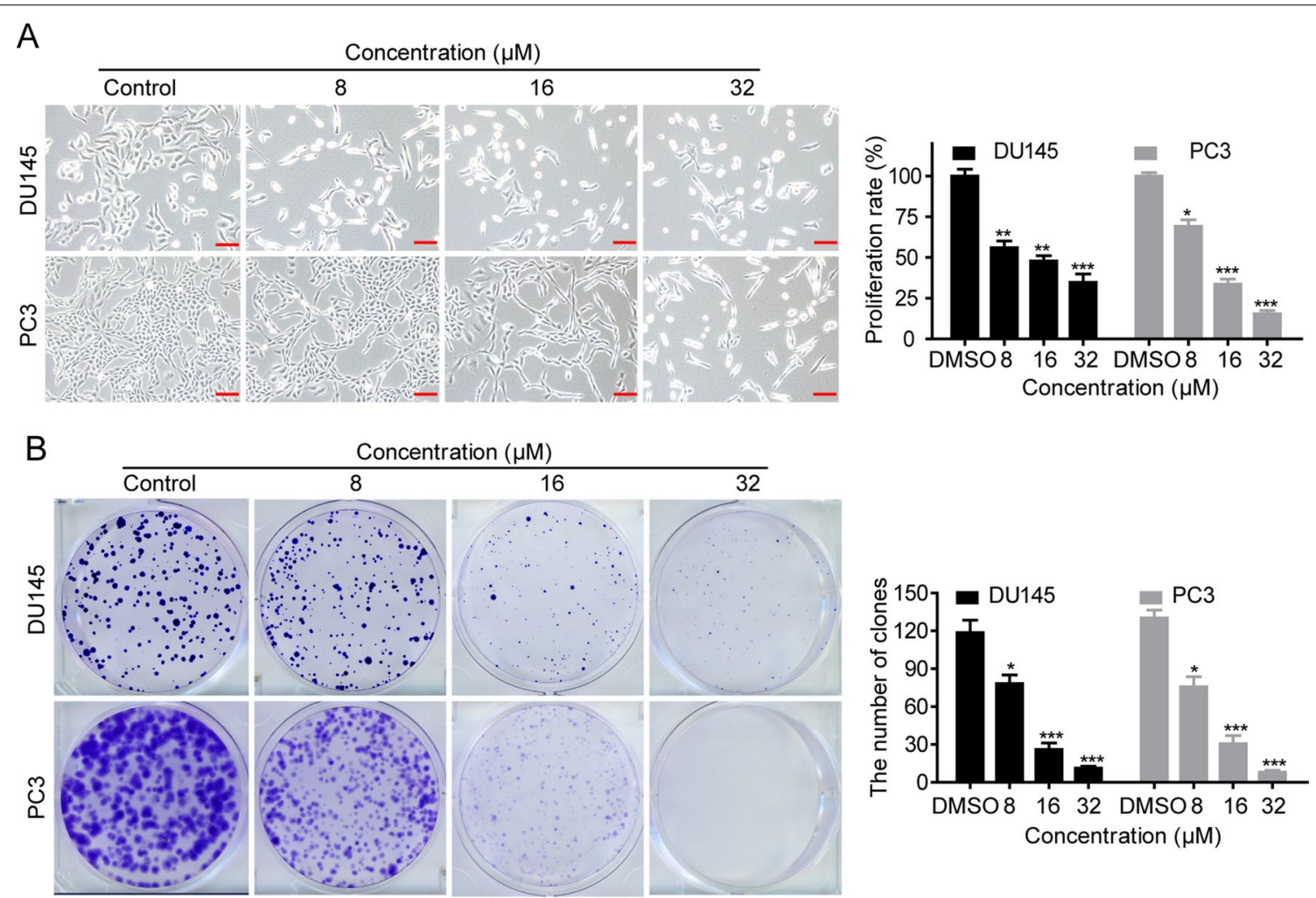

Fig. 1 The anti-proliferative effect of T-96 in human CaP lines. A Cell morphology of DU145 and PC3 cells after treatment with vehicle (0.05\% DMSO) or the indicated concentrations of T-96 for $48 \mathrm{~h}$ as captured with a microscope. Scale bar, $100 \mu \mathrm{m}$. The histogram shows quantification of the cell proliferation rate. B Colony formation assay was used to evaluate the in vitro growth of DU145 and PC3 cells after exposure to the indicated doses of T-96 for 7 days. The colonies were captured as images and the numbers presented using a histogram. All data are presented as the mean $\pm S D$ of three independent experiments. ${ }^{*} P<0.05$, ${ }^{*} P<0.01$ and ${ }^{* *} P<0.001$ versus vehicle 
A

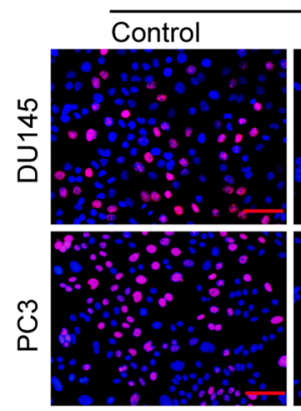

Concentration $(\mu \mathrm{M})$
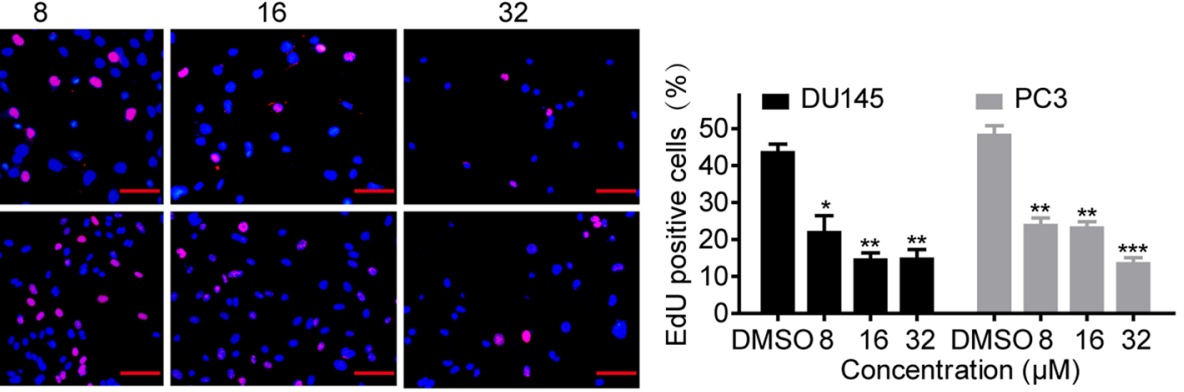

B

Concentration $(\mu \mathrm{M})$
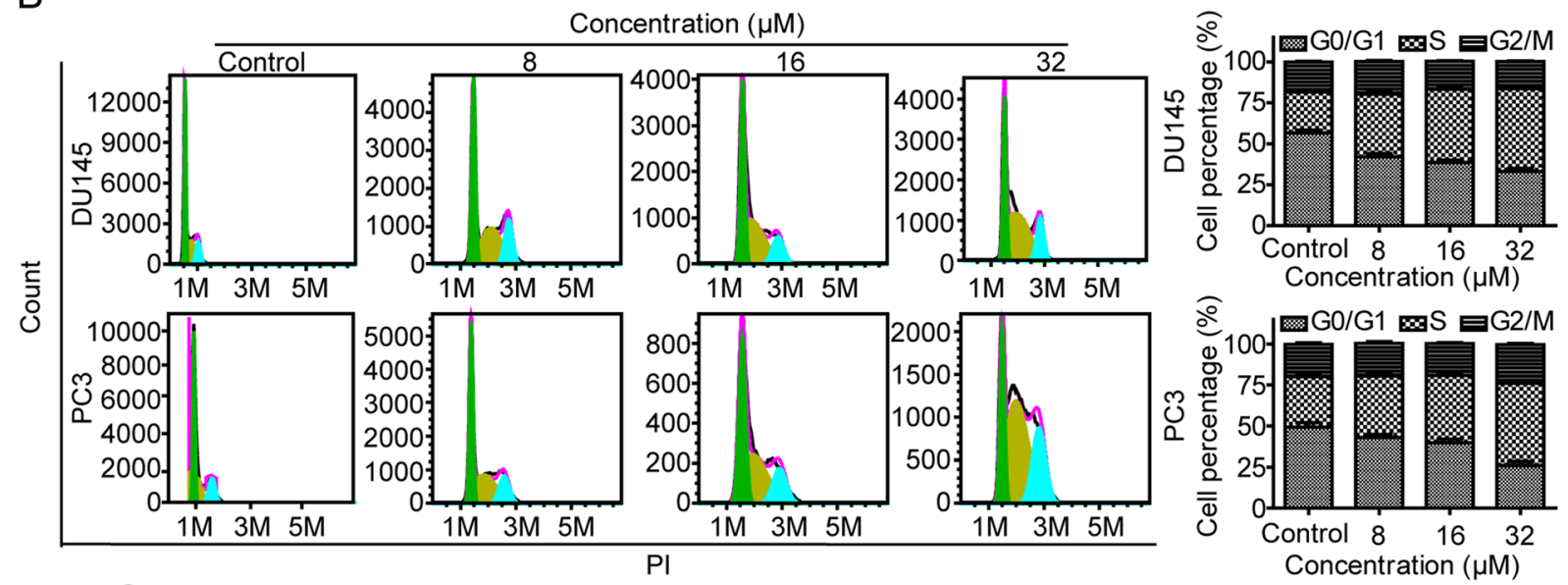

C
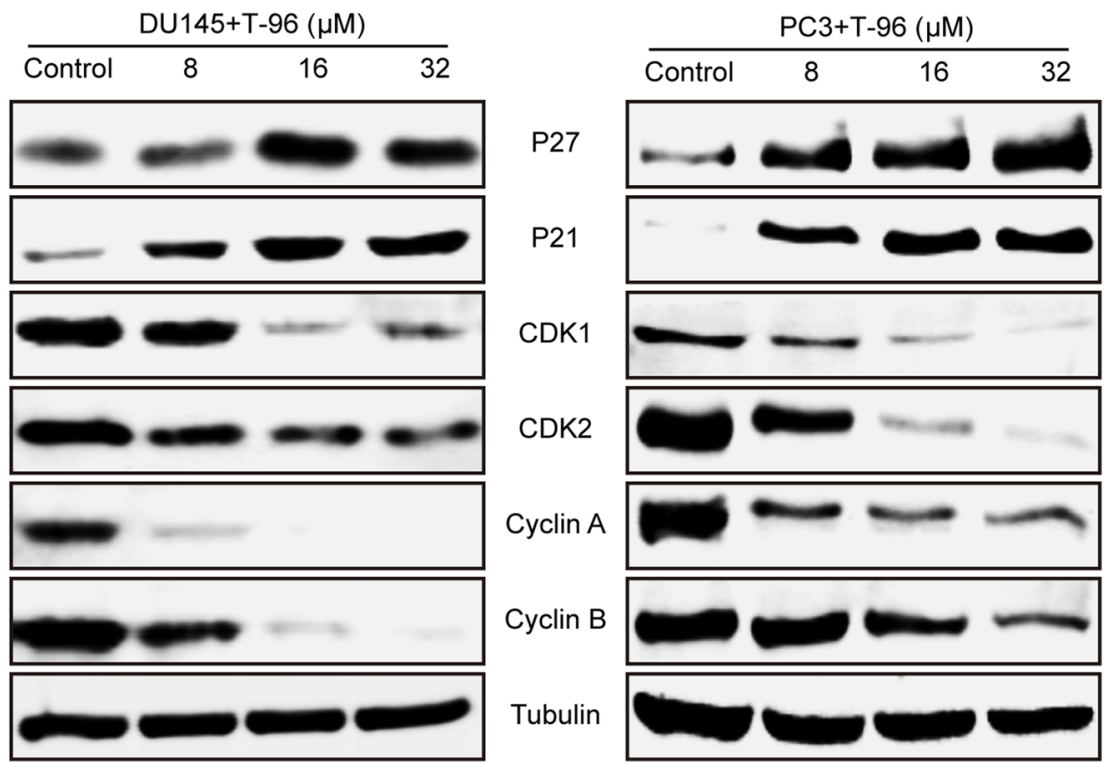

Fig. 2 T-96 exhibited anticancer effects by inducing cell cycle arrest at the S phase. A T-96 suppressed the proliferation of CaP cells. EdU-staining assay was conducted to access the effect of T-96 treatment for $48 \mathrm{~h}$ on cell proliferation. Scale bar, $100 \mu \mathrm{m}$. B Flow cytometry was used to quantify the proportion of DU145 and PC3 cells in the different stages of the cell cycle in the presence of vehicle or T-96. The percentages of cell population in different conditions were quantified using three independent experiments. C Effects of T-96 on the expression levels of S-phase related proteins in DU145 and PC3 cells were examined using western blot after exposure to T-96 for $48 \mathrm{~h}$. $\beta$-Tubulin was used as a loading control. All data are presented as the mean $\pm S D$ of three independent experiments. "**" represents $P<0.05$; "**" represents $P<0.01$; ${ }^{\prime * * * " ~ r e p r e s e n t s ~} P<0.001$ 
CDK2, but significantly increased the levels of P21 and P27 in a dose dependent manner in DU145 and PC3 cell lines (Fig. 2C). Taken together, these data demonstrated that T-96 inhibited cell proliferation by inducing cell cycle arrest of $\mathrm{CaP}$ cells in the $\mathrm{S}$-phase.

\section{T-96 activated the extrinsic -apoptosis signalling pathway in CaP cells}

To further determine if T-96 suppressed CaP cell proliferation by activating apoptosis, we conducted Annexin V-FITC/PI assay using flow cytometry after exposing the cells to T-96 for $48 \mathrm{~h}$. As indicated in Fig. 3A, T-96 significantly induced cell apoptosis in CaP cells and increased the proportion of cells in late-phase apoptosis (from 5.47 to $32.5 \%$ for DU145 cells, $\mathrm{P}<0.001$; from 3.03 to $33.8 \%$ for PC3 cells, $\mathrm{P}<0.001$ ) in a dose-dependent manner. We also assayed the expression levels of proteins associated with the extrinsic-apoptosis signaling pathway to determine if T-96 treatment activates this pathway. T-96 treatment induced a significant increase in the levels of Cleaved Caspase8 (C-Cas8), Cleaved Caspase3 (C-Cas3) and Cleaved PARP in a dose-dependent manner (Fig. 3B). Moreover, a specific caspase3 inhibitor, Z-VAD-FMK, significantly decreased the rate of apoptosis in DU145 and PC3 cells, suggesting that Z-VAD-FMK partially rescues cells from T-96-induced cell apoptosis (Fig. 3C). In summary, these data indicated that T-96 induced apoptosis in CaP cells through the activation of the extrinsicapoptosis signaling pathway.

T-96 induced ER stress by promoting the generation of ROS in prostate cells

Previous studies have revealed that ROS is involved in the development of ER stress and the induction of cell death [31-33]. To determine if T-96 induced the generation of ROS, DU145 and PC3 cells were incubated with the specific ROS-detecting fluorescent dye, 2',7'-dichlorofluorescein diacetate (DCF-DA), and ROS generation was measured using fluorescence microscopy. Different concentrations of T-96 induced significant production of ROS compared to the control group (Fig. 4A). Similarly, T-96 induced the expression of the oxidative stress responsive gene, nuclear factor-like 2 (NRF2), in a dose dependent manner, suggesting the occurrence of excessive accumulation of ROS within CaP cells (Fig. 4C). We further investigated if T-96 promoted ER stress by inducing accumulation of excessive intracellular ROS. Since the accumulation of polyubiquitinated proteins is an important marker of ER stress, we used western blot analysis to evaluate if T-96 affects the levels of total polyubiquitinated proteins in DU145 and PC3 cell lines. As shown in Fig. 4B, T-96 caused a remarkable increase in the levels of polyubiquitinated protein levels in a dose-dependent manner in DU145 and PC3 cells. UPR is an intracellular signaling pathway that is activated when there is accumulation of misfolded and unfolded proteins, and restores ER function by increasing protein folding ability and degrading the accumulated proteins $[9,10,34]$. T-96 increased the phosphorylation of PERK and significantly upregulated the protein levels of several UPR associated proteins, such as BIP, IRE1 $\alpha$, Ero1-L1 $\alpha$ and PDI, in a dose-dependent manner (Fig. 4C). ER stress is associated with alteration in $\mathrm{Ca}^{2+}$ homeostasis which in turn aggravates the ER stress leading to apoptotic cell death [35]. Therefore, we evaluated whether T-96 disturbs $\mathrm{Ca}^{2+}$ homeostasis by staining $\mathrm{CaP}$ cells with Furo-4/AM, a $\mathrm{Ca}^{2+}$ specific indicator, after treating the cells with different concentrations of T-96. Interestingly, T-96 increased intracellular fluorescence, suggesting that T-96 induced ER stress and the subsequent release of $\mathrm{Ca}^{2+}$ from the ER to the cytoplasm (Fig. 4D). In summary, these results demonstrated that T-96 induced ROS generation, which initiated ER stress and the subsequent accumulation of intracellular $\mathrm{Ca}^{2+}$.

\section{T-96 initiated autophagy but blocked autophagic flux to induce apoptosis}

Several studies have demonstrated that autophagy is activated during ER stress to promote the engulfment of stressed ER by autophagosome [11, 12, 36]. We investigated if T-96 treatment regulates autophagy. The induction of autophagy can be confirmed through the detection of punctate LC3 signals using immunofluorescence, or determining the LC3-II/LC3-I ratio using western blot. First, we used DU145 and PC3 cells transiently transfected with GFP-tagged LC3 to demonstrate the regulatory effect of T-96 on autophagy. From this assay, we observed that T-96 dramatically induced accumulation of GFP-LC3 puncta, which represents the number of autophagic vacuoles, and increased the LC3-II/LC3-I ratio, an indication of increased conversion of LC3-II in a dose-dependent manner in both DU145 and PC3 cells (Fig. 5A, B). The three main pathways involved in the regulation of autophagy are adenosine monophosphate-activated protein kinase (AMPK), mammalian target of rapamycin (mTOR) and mitogen-activated protein kinases (MAPK/ERK) signaling pathways [37, 38]. We next explored whether the T-96-induced initiation of autophagy was effected through the AMPK, mTOR or MAPK/ERK pathways. We found that T-96 significantly increased the phosphorylation levels of AMPK and MAPK/ERK but reduced the phosphorylation levels of mTOR in CaP cells in a dose-dependent manner (Fig. 5B). There is accumulating evidence that suggests that drug-mediated activation of MAPK/ERK can impair autophagy maturation by disrupting the fusion between 
A

$\bar{\alpha}$

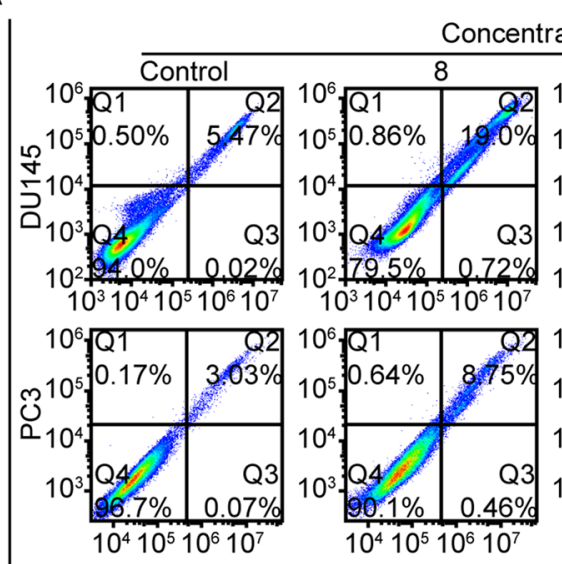

Concentration $(\mu \mathrm{M})$
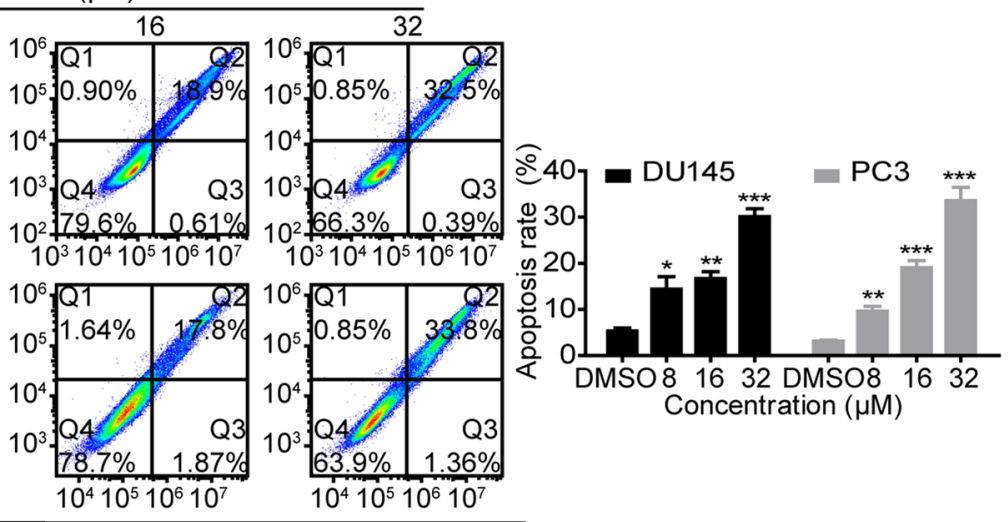

B

Annexin V-FITC

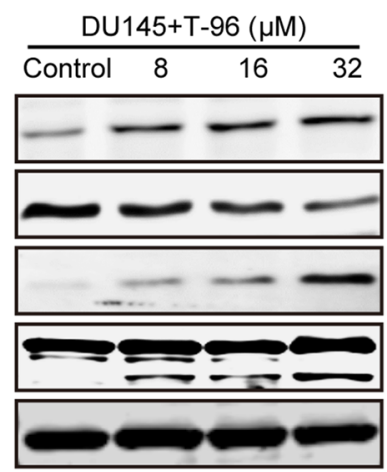

C

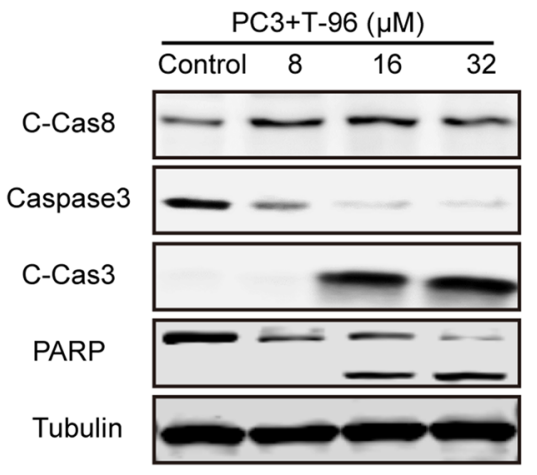

Z-VAD-FMK

$50 \mu \mathrm{M}$

T-96

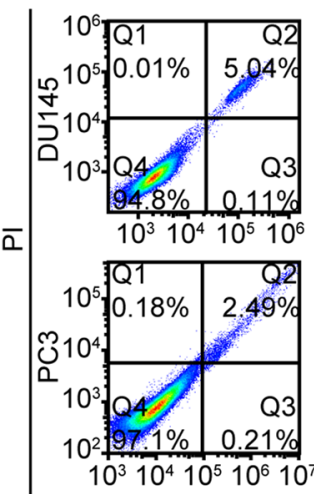

Q3

$10^{3}$
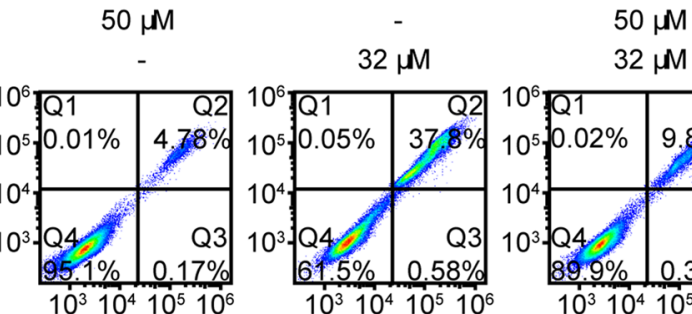

$50 \mu \mathrm{M}$

$10^{6}$

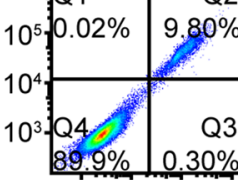

$10^{3} 10^{4} 10^{5} 10^{6} \quad 10^{3} 10^{4} 10^{5} 10^{5}$
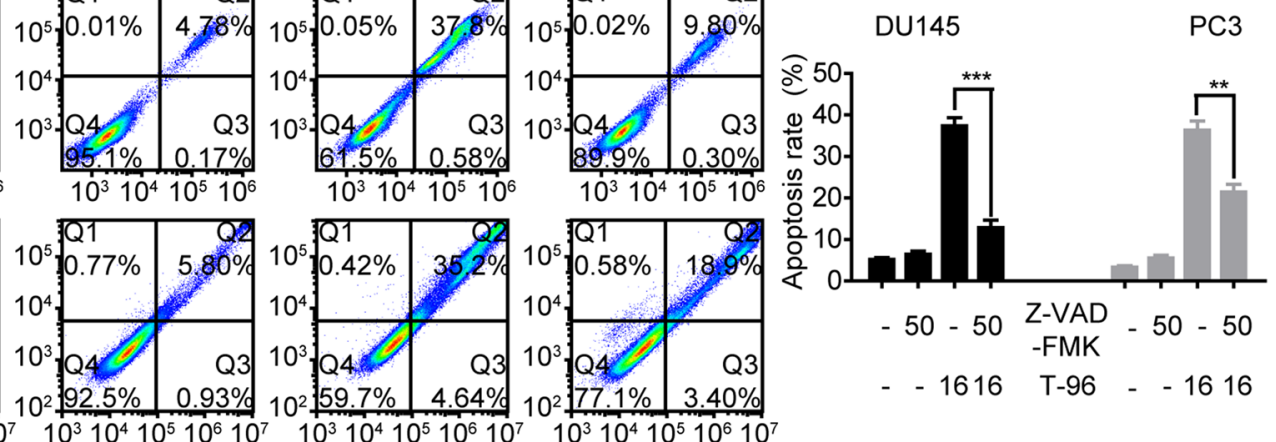

Annexin V-FITC

Fig. 3 T-96 induced caspase-3-dependent apoptotic cell death in human CaP cells. A, C Apoptotic cell death in DU145 and PC3 cells was assessed using flow cytometry after treatment with T-96, Z-VAD-FMK (50 $\mu \mathrm{M})$, or T-96 in combination with Z-VAD-FMK (50 $\mu$ M) for $48 \mathrm{~h}$. B The expression of indicated proteins in DU145 and PC3 cells were examined using western blotting after exposure to T-96 for $48 \mathrm{~h}$. $\beta$-Tubulin was used as the loading control. Data represents the mean \pm SD of three independent experiments. ${ }^{*} \mathrm{P}<0.05,{ }^{* *} \mathrm{P}<0.01$ and ${ }^{* * *} \mathrm{P}<0.001$

autophagosome and lysosome [39, 40]. Therefore, we transfected CaP cells with double tagged mCherry-GFPLC3B reporter to determine if T-96 modulates autophagic flux by regulating the fusion efficiency of autophagosome and lysosome. Yellow fluorescence represented the number of non-acidic autophagosomes, whereas red fluorescence labeled autolysosomes. There was remarkable increase in the number of yellow fluorescent vesicles in 


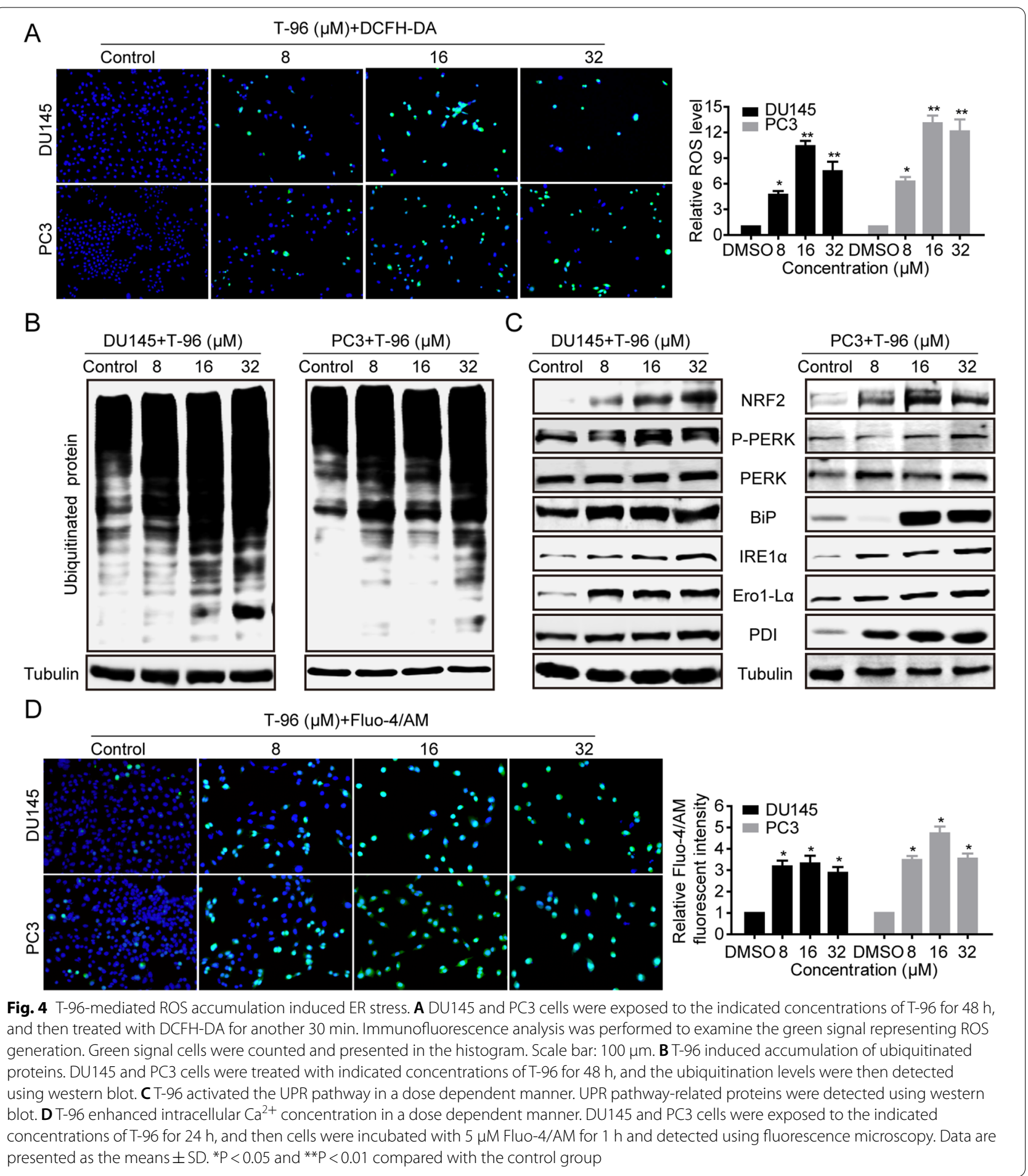

DU145 and PC3 cells exposed to T-96 for $12 \mathrm{~h}$ compared to the control (Fig. 5C). This implied that there was a defect in the fusion between autophagosome and lysosome which perturbed autophagic flux. It has been previously reported that inhibition of autophagic flux leads to the accumulation of polyubiquinated proteins which subsequently induces ER stress [9, 10, 14, 31-33]. Consistent with these reports, we found that the combination of T-96 and rapamycin, an inhibitor of mTOR, slightly increased apoptosis compared to T-96 treatment alone. 
In contrast, the combination of T-96 and chloroquine, an autophagic flux inhibitor that decreases autophagosome-lysosome fusion, significantly induced apoptosis in $\mathrm{CaP}$ cells implying that inhibition of autophagic flux enhanced T-96-mediated induction of apoptosis (Fig. 5D). Taken together, these results revealed that T-96 initiates autophagy but suppresses autophagic flux, which induces apoptosis in DU145 and PC3 cells.

\section{T-96 enhanced sensitivity of CaP cells to cisplatin through induction of ER stress and apoptosis}

Several studies have demonstrated that chemotherapy or radiotherapy-induced autophagy may lead to the development of drug resistance thus protecting cancer cells from apoptosis. On the other hand, the suppression of autophagic flux can improve the sensitivity of cells to chemotherapy as a result of induction of cell death [41-43]. Since our previous assays had demonstrated that T-96 modulates autophagy, we explored the effect of T-96 on the sensitivity of CaP cells to chemotherapy drugs, by treating $\mathrm{CaP}$ cells with T-96 alone or in combination with cisplatin. We examined the growthinhibitory effects of T-96 and cisplatin co-treatment in DU145 and PC3 cells exposed to various concentrations of T-96 $(0,8$, and $16 \mu \mathrm{M})$ and cisplatin $(0,1.25,2.5,5,10$ and $20 \mu \mathrm{M})$ alone or in combination for $48 \mathrm{~h}$. Results of the MTT assay showed that co-treatment of DU145 and PC3 cells with T-96 and cisplatin significantly suppressed cell proliferation, whereas monotherapy was associated with low levels of cytotoxicity (Fig. 6A). Next, we evaluated the effect of T-96 and cisplatin, co-treatment on the induction of apoptosis in CaP cells and found that combined treatment caused a higher apoptotic rate than that of monotherapy (Fig. 6B). Consistently, the results of western blot showed that T-96 and cisplatin co-treatment increased the levels of C-Cas3 and PARP compared to treatment with cisplatin alone (Fig. 6C). In addition, T-96 and cisplatin co-treatment up-regulated the expression of NRF2 and the UPR associated proteins, such as p-PERK, BIP, IRE1 $\alpha$, Ero1-L1 $\alpha$ and PDI compared to the expression under single-agent treatment (Fig. 6D). This indicated that co-treatment was more effective in initiating oxidative stress response and UPR than monotherapy. Taken together, these results suggest that T-96 improved the chemosensitivity of $\mathrm{CaP}$ cells to cisplatin.

\section{Discussion}

Although there have been significant advances in therapeutic strategies against $\mathrm{CaP}$, the emergence of androgen-independence has increased the incidences of unfavourable prognosis and resistance to radio- and chemo-therapy [4]. Therefore, there is urgent need to develop novel agents that can inhibit cell growth and proliferation, overcome multidrug resistance and reduce the recurrence of $\mathrm{CaP}$ cells. It has been reported that T-96 has anti-cancer effects against various malignant carcinomas, including melanoma [24], glioblastoma [25], breast cancer [26] and pancreatic cancer [27]. However, its effects on cell growth and possible molecular mechanisms against $\mathrm{CaP}$ have not yet been explored. In the current study, we demonstrated that T-96 was a potent inhibitor of $\mathrm{CaP}$ by inducing cell cycle arrest at $\mathrm{S}$-phase and activating the extrinsic-apoptosis signalling pathway. Mechanistically, T-96 induced ER stress, initiated autophagy but suppressed autophagic flux and induced apoptosis of $\mathrm{CaP}$ cells through the extrinsic pathway. This implies that the ER stress-induced suppression of autophagic flux after treatment with T-96 promoted caspase 8-dependent external apoptosis pathway to inhibit $\mathrm{CaP}$ cells. In addition, our findings indicated that T-96 works in synergy with cisplatin to enhance cisplatinmediated cytotoxicity in $\mathrm{CaP}$ cells.

It has been reported that perturbations in ER functions induced by changes in tumor microenvironment or the effects of anti-tumor drugs can trigger ER stress, can lead to the accumulation of unfolded proteins in the ER lumen [44, 45]. ROS overload is the most important inducer of ER stress in the cells [46]. ER stress plays opposing roles in tumour, by either promoting cell survival or inducing cell death. Indeed, it was indicated that low levels of UPR and ER stress act as an accommodative mechanism to promote survival of cancerous cells by inducing multiple antiapoptotic mechanisms. This protects the cells from chemotherapy-mediated

\footnotetext{
(See figure on next page.)

Fig. 5 T-96 initiated autophagy but blocked autophagic flux in human CRC cells. A The punctate staining pattern of LC3 was detected using high content analysis system-operetta CLS ${ }^{\mathrm{TM}}$ in DU145 and PC3 cells after treatment with increasing concentrations of T-96 for 48 h. Scale bar, $10 \mu \mathrm{m}$. B The expression levels of proteins involved in initiation of autophagy were detected after exposure to T-96 using western blot. $\beta$-Tubulin was used as a loading control. C T-96 suppressed the autophagic flux in PC3 cells overexpressing mCherry-EGFP-LC3. Both cells were treated with indicated concentrations of T-96 for $24 \mathrm{~h}$ and then observed with fluorescent microscopy. Scale bar, $10 \mu \mathrm{m}$. Quantitative analysis of the autophagosome accumulation in T-96-treated cells. Yellow dots representing the autophagosomes were counted in three independent experiments. Red fluorescence indicates autophagolysosomes. D The suppression of Autophagic flux significantly increased apoptosis. DU145 and PC3 cell lines were treated with rapamycin, chloroquine, T-96, rapamycin in combination with T-96, and chloroquine in combination with T-96. The rate of apoptosis was measured using flow cytometry. Data represent the mean \pm SD of three independent experiments. ${ }^{* *}<<0.01$ and ${ }^{* *} P<0.001$ compared with the control group
} 

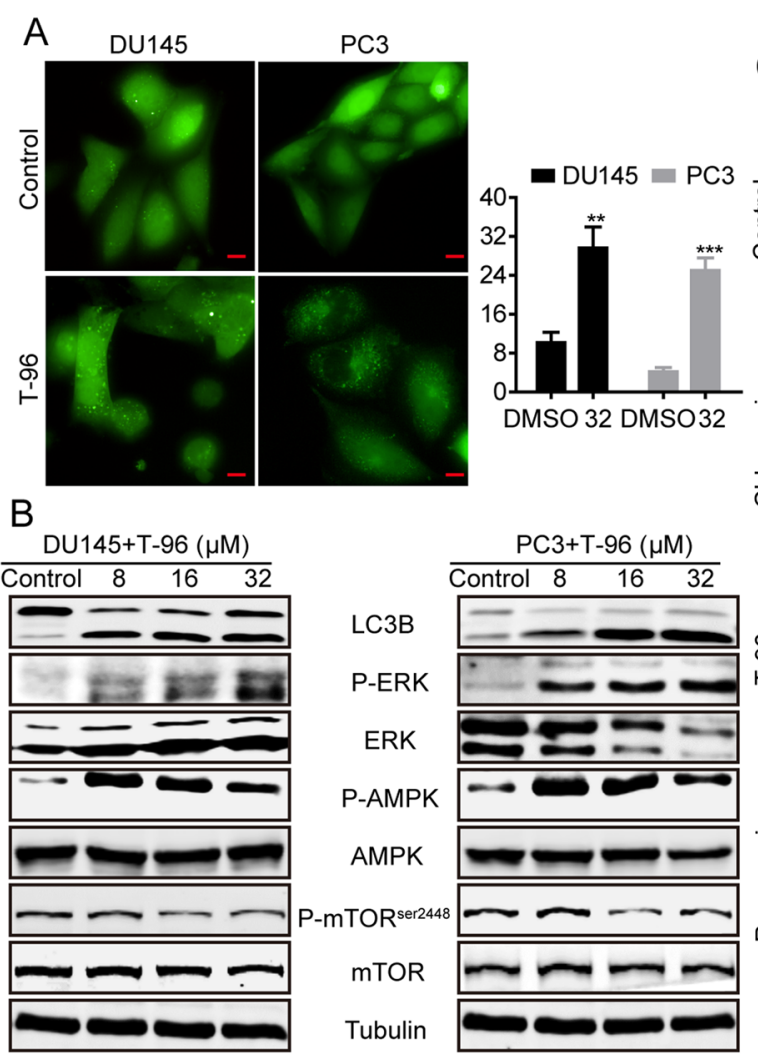

C

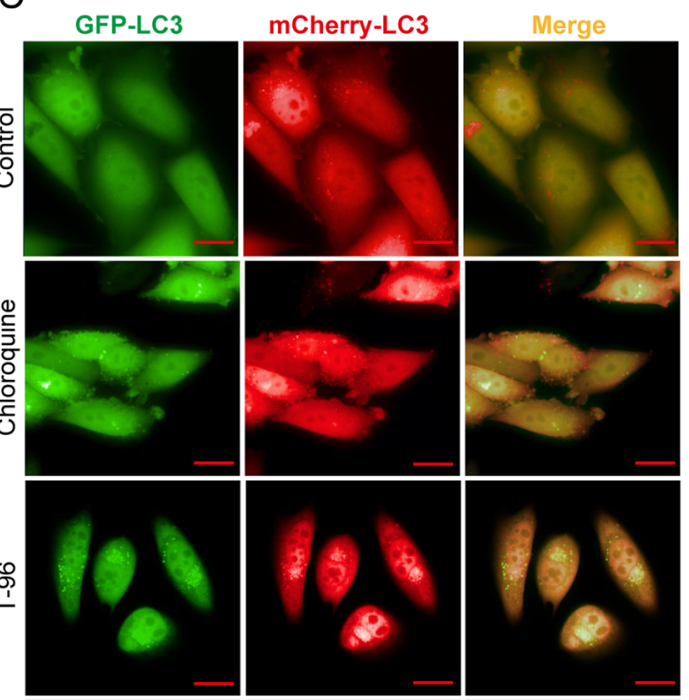

D
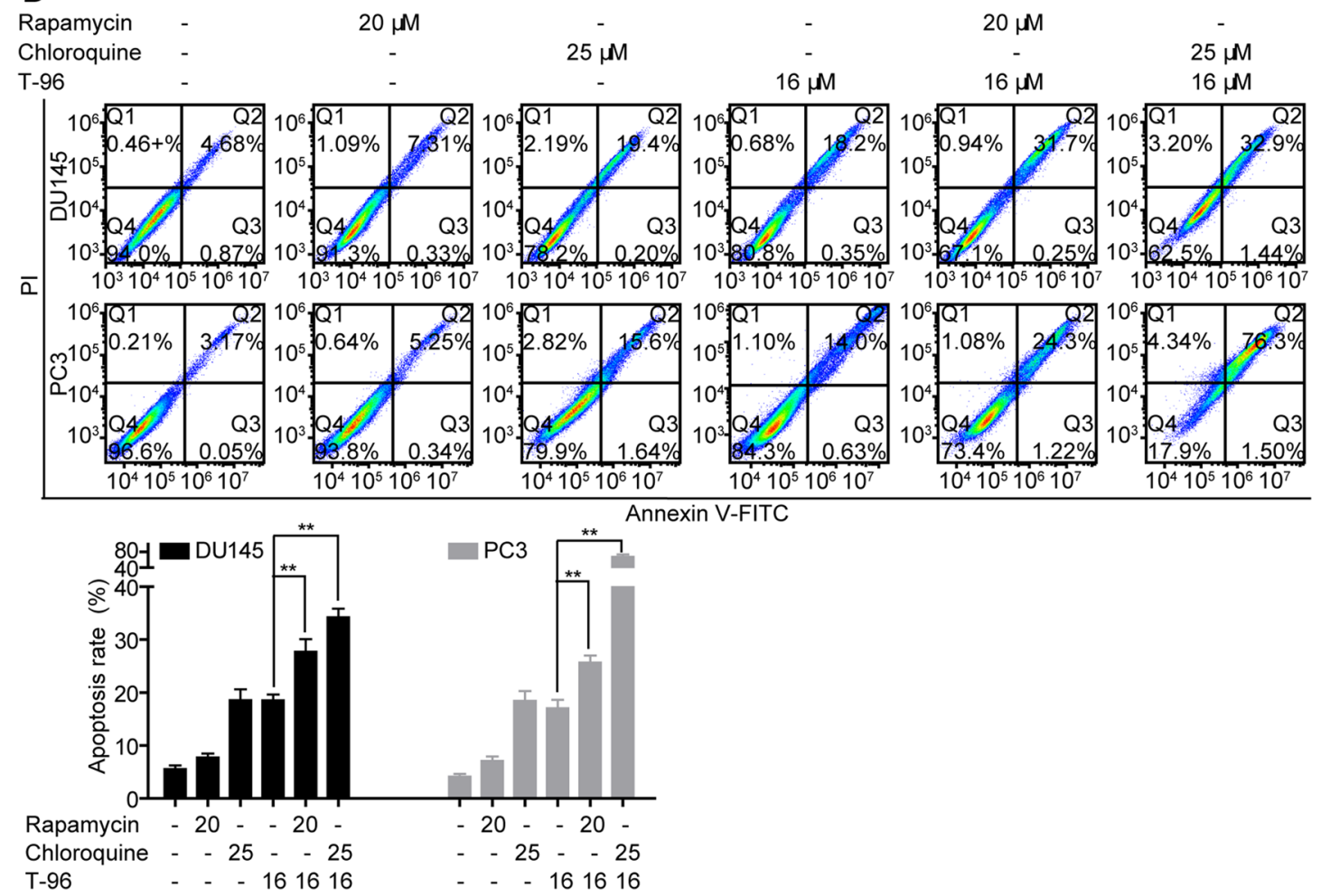

Fig. 5 (See legend on previous page.) 


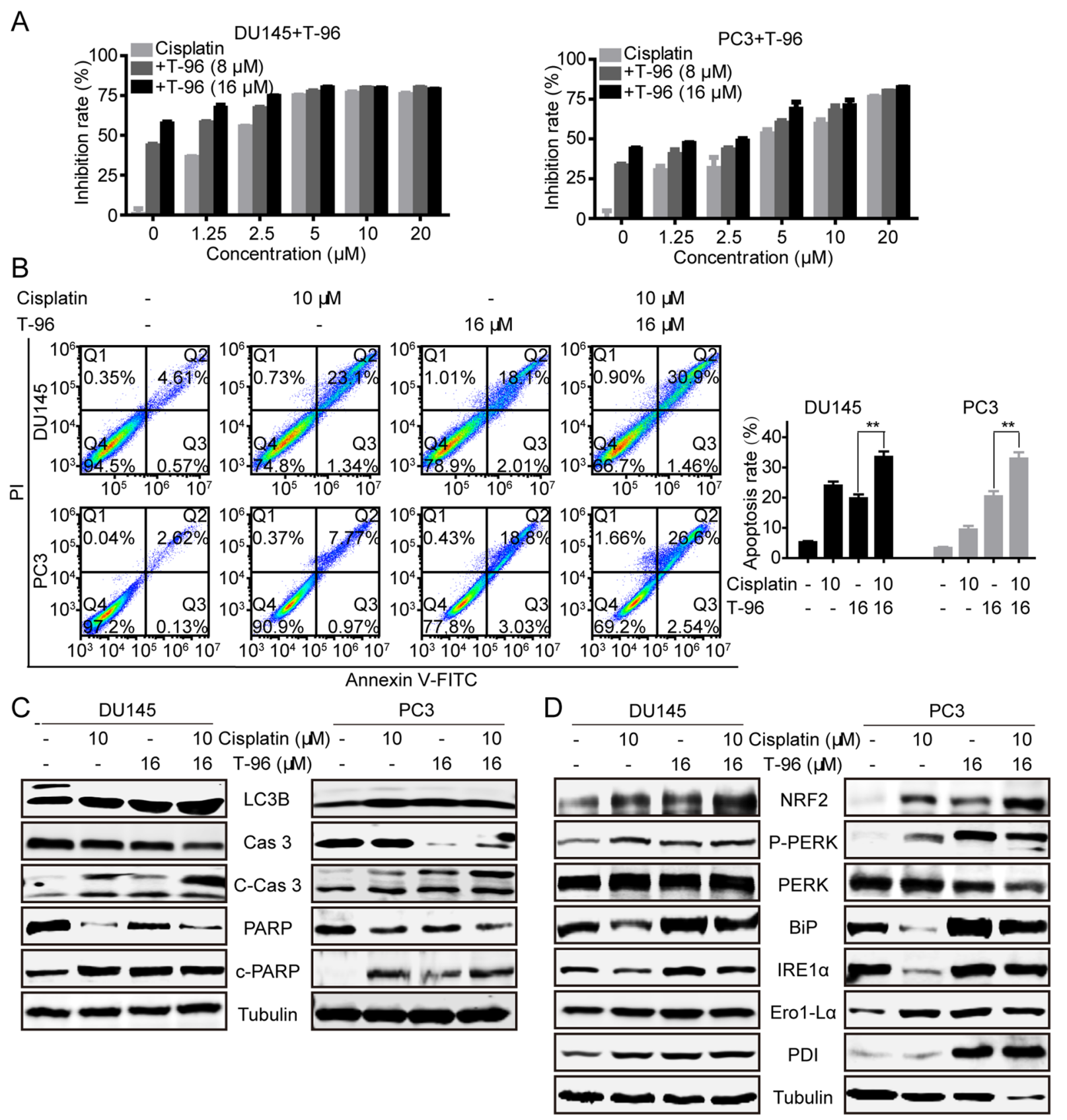

Fig. 6 T-96 enhanced sensitivity of human CaP cells to cisplatin. A T-96 enhanced the cytotoxic effect of cisplatin against CaP cells. DU145 and PC3 cells were treated with indicated concentrations of T-96 and cisplatin for $48 \mathrm{~h}$. MTT was conducted to assess the effect of T-96 on cisplatin-induced cytotoxicity in CaP cells. B, C Combined T-96 and cisplatin treatment induced a higher rate of apoptosis than that of monotherapy. DU145 and PC3 cells were treated with T-96, cisplatin, and T-96 combined with cisplatin for $48 \mathrm{~h}$, and then flow cytometry was used to assess the level of apoptosis-induced cell death. The expression levels of indicated proteins were detected using western blot. D T-96 and cisplatin co-treatment was more effective in initiating oxidative stress response and UPR. Western blot was used to examine the levels of NRF 2 and the UPR associated proteins after treatment with T-96 combined with cisplatin. $\beta$-Tubulin was used as a loading control. Data represent the mean \pm SD of three independent experiments. ${ }^{* *} \mathrm{P}<0.01$ compared with the control group

cell death, and thus plays a major role in inducing chemotherapy drug resistance [47-49]. On the other hand, excessive levels of ER stress overcome the protective capability of UPR and induce apoptosis of the cancerous cells [49-51]. In line with that, we found that T-96 treatment remarkably induced high levels of 
ROS, up-regulated the expression of the UPR hallmarks p-PERK, IRE1 $\alpha$, Ero1-L1 $\alpha$ and PDI, and significantly increased intracellula $\mathrm{Ca}^{2+}$ levels in CaP cells. This suggests that T-96 treatment induced ER stress.

In addition, ER stress is associated with the initiation of autophagy during normal physiological and pathological states as well as during chemotherapy [52-55]. Autophagy is a vital, dynamic and evolutionarily conserved process aimed at elimination of unnecessary or dysfunctional cellular components through degradation in autophagolysosomes. Autophagy has a double-edged sword role in cancerous cells as it can either increase or decrease survival of the cells [56, 57]. Autophagy is mainly induced when serine/threonine kinase UNC51-like kinase 1 (ULK1) is phosphorylated by either AMPK or mTOR [58]. We found that exposure to T-96 remarkably decreased the levels of LC3I protein and p-mTOR (Ser2448), and dramatically increased the levels of p-AMPK (Thr172) in CaP cells, indicating that T-96 induced autophagy through the AMPK and mTOR pathways. However, some reports have indicated that suppression of mTOR blocks the autophagic flux leading to the accumulation of autophagosomes rather than initiating autophagy $[59,60]$. This is consistent with our observation that down-regulation of mTOR phosphorylation was vital for T-96-induced impairment of autophagic flux.

MAPK/ERK activation regulates various cell responses such as proliferation, migration and differentiation [61]. Although high levels of MAPK/ERK phosphorylation have been detected in many malignant tumors, MAPK/ ERK activation is not always involved in promotion of cell survival as it also plays a role in processes associated with cell death such as autophagy, apoptosis and senescence [61, 62]. However, the exact effect of MAPK/ ERK on activation and maturation of autophagy has not been defined and generates controversial results [38]. Increasing evidence demonstrates that drug treatment prolongs the activation of MAPK/ERK pathway which subsequently blocks the maturation process of autophagy $[39,40]$. This is consistent with findings from our study indicating that treatment with T-96 activated autophagy and ERK but impaired autophagic flux. We inferred that T-96-mediated activation of ERK plays an important role in the initiation of autophagy and blockage of autophagic flux. Moreover, activation of MAPK/ERK has been reported to impair autophagy process by promoting the degradation of Fork head Box O1 (FOXO1), a protein associated with maintenance of autophagic flux in cancer cells $[63,64]$. It will be interesting to evaluate whether the T-96-induced activation of MPAK/ERK is effected by targeting FOXO1 and determine how ER stress initiates autophagy and impairs autophagic flux in CaP cells.
Recently, growing results have indicated that chemotherapy or radiotherapy-induced autophagy can lead to development of drug resistance whereas the impairment of autophagic flux can improve the sensitivity of cells to chemotherapy by inducing cell death [41-43]. Thus, novel autophagy inhibitors are potential candidates for increasing the efficacy of chemotherapeutic drugs against cancer. In the current study, we found that T-96 enhanced the sensitivity of $\mathrm{CaP}$ cells to cisplatin by regulating ER stress-induced autophagy. Therefore, since T-96 exhibits anticancer activity, the combination of T-96 with other chemotherapeutic drugs may be an effective therapeutic strategy for cancer treatment.

\section{Conclusions}

In conclusion, our study demonstrates that T-96 inhibits the survival of $\mathrm{CaP}$ cells by inducing cell cycle arrest and apoptosis and works synergistically with cisplastin to inhibit growth of $\mathrm{CaP}$ cells. This effect may be due to the induction of prolonged ER stress, which regulates autophagy and activates apoptosis. Our findings suggest that T-96 is a specific regulator of ER stress and autophagy and is a potential candidate for adjuvant therapy for CaP.

\section{Abbreviations \\ AMPK: Adenosine monophosphate-activated protein kinase; BiP: Immu- noglobulin heavy chain binding protein; ER: Endoplasmic reticulum; EdU: 5-Ethynyl-2'-deoxyuridine; IRE1a: Inositol-requiring enzyme 1a; mTOR: Mam- malian target of rapamycin; MAPK/ERK: Mitogen-activated protein kinases; NRF2: Nuclear factor-like 2; PERK: Double-stranded RNA-dependent protein kinase (PKR)-like endoplasmic reticulum kinase; PDI: Protein-disulfide isomer- ase; UPR: Unfolded protein response.}

\section{Supplementary Information}

The online version contains supplementary material available at https://doi. org/10.1186/s40659-021-00350-6.

Additional file 1: Figure S1.The anti-proliferative activity of T-96 onhuman CaP lines DU145 and PC3. (A)The chemical structure of T-96. (B)The inhibition rates of T-96 on DU145 and PC3 cells. Both DU145 and PC3 cellswere exposed to indicated concentrations of T-96 for 24, 48 and $72 \mathrm{~h}$. MTT wasperformed to measure cell viability and growth. $(\mathbf{C}) I C_{50}$ values of T-96 in DU145 and PC3 cells were calculated. (D) IC $C_{50}$ valueof T-96 in normal adult prostatic epithelial cell line PNT1A. (E) IC 50 values of cisplatinin DU145 and PC3 cells.Cisplatin was used as a positive drug.

\section{Acknowledgements}

Not applicable.

\section{Authors' contributions}

$D Y, Y Z, L H, Y T$ and $C H$ conducted the experimental research and data acquisition. DT, LG and ZC contributed to the study design and data analysis. DY, $Y Z, J H$ and JL wrote and edited the manuscript. All authors revised and commented on the manuscript. Therefore, all authors have full access to all the data in the study and take responsibility for the integrity and security of the data. All authors read and approved the final manuscript. 


\section{Funding}

This research was funded by the Basic Research and Frontier Program of Chongqing Science and Technology Bureau (cstc2019jcyj-msxmX0727, cstc2020jcyj-msxmX0595, cstc2020jcyj-msxmX0004 and cstc2020jcyjmsxmX0733), Science and Technology Research Program of Chongqing Municipal Education Commission (KJZD-K20200130 and KJQN201901331) and Scientific Research Foundation of the Chongqing University of Arts and Sciences (2017RBX11, Y2019XY19 and Y2020XY14).

\section{Availability of data and materials}

The datasets and materials obtained and analyzed during the current study were available from the corresponding authors in a reasonable request.

\section{Declarations}

\section{Ethics approval and consent to participate}

Not applicable.

\section{Consent for publication}

Not applicable.

\section{Competing interests}

The authors declare that they have no competing interests.

\section{Author details}

${ }^{1}$ College of Pharmacy, National \& Local Joint Engineering Research Center of Targeted and Innovative Therapeutics, Chongqing Key Laboratory of Kinase Modulators as Innovative Medicine, Chongqing University of Arts and Sciences, Chongqing 402160, China. ${ }^{2}$ College of Pharmaceutical Sciences and Chinese Medicine, Southwest University, Chongqing 400715, China.

Received: 12 April 2021 Accepted: 22 August 2021

Published online: 06 September 2021

\section{References}

1. Martignano F, Rossi L, Maugeri A, Gallà V, Conteduca V, De Giorgi U, Casadio V, Schepisi G. Urinary RNA-based biomarkers for prostate cancer detection. Clin Chim Acta. 2017;473:96-105.

2. Dai C, Heemers H, Sharifi N. Androgen signaling in prostate cancer. Cold Spring Harb Perspect Med. 2017;7(9):a030452.

3. Yap TA, Smith AD, Ferraldeschi R, Al-Lazikani B, Workman P, De Bono JS. Drug discovery in advanced prostate cancer: translating biology into therapy. Nat Rev Drug Discov. 2016;15(10):699.

4. Valerio M, Emberton M, Eggener SE, Ahmed HU. The challenging landscape of medical device approval in localized prostate cancer. Nat Rev Urol. 2016;13(2):91.

5. Fong ZV, Tanabe KK. The clinical management of hepatocellular carcinoma in the United States, Europe, and Asia: a comprehensive and evidence-based comparison and review. Cancer. 2014;120(18):2824-38.

6. Anelli T, Sitia R. Protein quality control in the early secretory pathway. EMBO J. 2008;27(2):315-27.

7. Tabas I, Ron D. Integrating the mechanisms of apoptosis induced by endoplasmic reticulum stress. Nat Cell Biol. 2011;13(3):184-90.

8. Jeong JS, Kim SR, Cho SH, Lee YC. Endoplasmic reticulum stress and allergic diseases. Curr Allergy Asthma Rep. 2017;17(12):82.

9. Grootjans J, Kaser A, Kaufman RJ, Blumberg RS. The unfolded protein response in immunity and inflammation. Nat Rev Immunol. 2016;16(8):469.

10. Arensdorf A, Diedrichs D, Rutkowski T. Regulation of the transcriptome by ER stress: non-canonical mechanisms and physiological consequences. Front Genet. 2013;4:256.

11. Hetz C. The unfolded protein response: controlling cell fate decisions under ER stress and beyond. Nat Rev Mol Cell Biol. 2012;13(2):89-102.

12. Liu M-q, Chen Z, Chen L-x. Endoplasmic reticulum stress: a novel mechanism and therapeutic target for cardiovascular diseases. Acta Pharmacol Sin. 2016;37(4):425-43.
13. Dandekar A, Mendez R, Zhang K. Cross talk between ER stress, oxidative stress, and inflammation in health and disease. In: Methods in molecular biology. Clifton: Humana Press; 2015. p. 205-14.

14. Shore GC, Papa FR, Oakes SA. Signaling cell death from the endoplasmic reticulum stress response. Curr Opin Cell Biol. 2011;23(2):143-9.

15. Tao X, Younger J, Fan FZ, Wang B, Lipsky PE. Benefit of an extract of Tripterygium wilfordii Hook $F$ in patients with rheumatoid arthritis: a doubleblind, placebo-controlled study. Arthritis Rheum. 2002;46(7):1735-43.

16. Ji W, Li J, Lin Y, Song Y-n, Zhang M, Ke Y, Ren Y, Deng X, Zhang J, Huang F. Report of 12 cases of ankylosing spondylitis patients treated with Tripterygium wilfordii. Clin Rheumatol. 2010;29(9):1067-72.

17. Tao X, Fan F, Hoffmann V, Gao CY, Longo NS, Zerfas P, Lipsky PE. Effective therapy for nephritis in (NZB $\times$ NZW) F1 mice with triptolide and tripdiolide, the principal active components of the Chinese herbal remedy Tripterygium wilfordii Hook F. Arthritis Rheum. 2008;58(6):1774-83.

18. Han R, RostamiHoffmann V, Gao CY, Longotz U. Triptolide in the treatment of psoriasis and other immune-mediated inflammatory diseases. Br J Clin Pharmacol. 2012;74(3):424-36.

19. Luo D, Zhao J, Rong J. Plant-derived triterpene celastrol ameliorates oxygen glucose deprivation-induced disruption of endothelial barrier assembly via inducing tight junction proteins. Phytomedicine. 2016;23(13):1621-8.

20. Mujumdar N, Mackenzie TN, Dudeja V, Chugh R, Antonoff MB, BorjaCacho D, Sangwan V, Dawra R, Vickers SM, Saluja AK. Triptolide induces cell death in pancreatic cancer cells by apoptotic and autophagic pathways. Gastroenterology. 2010;139(2):598-608.

21. Oliveira AR, Beyer G, Chugh R, Skube SJ, Majumder K, Banerjee S, Sangwan V, Li L, Dawra RK, Subramanian S. Triptolide abrogates growth of colon cancer and induces cell cycle arrest by inhibiting transcriptional activation of E2F. Lab Invest. 2015;95(6):648-59.

22. Zhao X, Gao S, Ren H, Huang H, Ji W, Hao J. Inhibition of autophagy strengthens celastrol-induced apoptosis in human pancreatic cancer in vitro and in vivo models. Curr Mol Med. 2014;14(4):555-63.

23. Xu W, Lin Z, Yang C, Zhang Y, Wang G, Xu X, Lv Q, Ren Y, Dong Y. Immunosuppressive effects of demethylzeylasteral in a rat kidney transplantation model. Int Immunopharmacol. 2009;9(7-8):996-1001.

24. Zhao Y, He J, Li J, Peng X, Wang X, Dong Z, Zhao E, Liu Y, Wu Z, Cui $H$. Demethylzeylasteral inhibits cell proliferation and induces apoptosis through suppressing MCL1 in melanoma cells. Cell Death Dis. 2017;8(10):e3133.

25. Zhang K, Fu G, Pan G, Li C, Shen L, Hu R, Zhu S, Chen Y, Cui H. Demethylzeylasteral inhibits glioma growth by regulating the miR-30e-5p/MYBL2 axis. Cell Death Dis. 2018;9(10):1-14.

26. Li L, Ji Y, Fan J, Li F, Li Y, Wu M, Cheng H, Xu C. Demethylzeylasteral (T-96) inhibits triple-negative breast cancer invasion by blocking the canonical and non-canonical TGF- $\beta$ signaling pathways. Naunyn Schmiedebergs Arch Pharmacol. 2019;392(5):593-603.

27. Wang F, Tian X, Zhang Z, Ma Y, Xie X, Liang J, Yang C, Yang Y. Demethylzeylasteral (ZST 93) inhibits cell growth and enhances cell chemosensitivity to gemcitabine in human pancreatic cancer cells via apoptotic and autophagic pathways. Int J Cancer. 2018;142(9):1938-51.

28. Al Refaey HR, Newairy A-SA, Wahby MM, Albanese C, Elkewedi M, Choudhry MU, Sultan AS. Manuka honey enhanced sensitivity of HepG2, hepatocellular carcinoma cells, for doxorubicin and induced apoptosis through inhibition of Wnt/ $\beta$-catenin and ERK1/2. Biol Res. 2021;54(1):1-16.

29. Zhang Y-J, Xu Z-G, Li S-Q, He L-J, Tang Y, Chen Z-Z, Yang D-L. Benzimidazoisoquinoline derivatives inhibit glioblastoma cell proliferation through down-regulating Raf/MEK/ERK and PI3KJAKT pathways. Cancer Cell Int. 2018;18(1):1-12.

30. Chen HY, He LJ, Li SQ, Zhang YJ, Huang JH, Qin HX, Wang JL, Li QY, Yang DL. A derivate of benzimidazole-isoquinolinone induces SKP2 transcriptional inhibition to exert anti-tumor activity in glioblastoma cells. Molecules. 2019;24(15):2722.

31. Shen M, Wang L, Wang B, Wang T, Yang G, Shen L, Guo X, Liu Y, Xia Y, Jia L. Activation of volume-sensitive outwardly rectifying chloride channel by ROS contributes to ER stress and cardiac contractile dysfunction: involvement of CHOP through Wnt. Cell Death Dis. 2014;5(11):e1528.

32. Chen Y, Liu JM, Xiong XX, Qiu XY, Pan F, Liu D, Lan SJ, Jin S, Yu SB, Chen $X Q$. Piperlongumine selectively kills hepatocellular carcinoma cells and 
preferentially inhibits their invasion via ROS-ER-MAPKs-CHOP. Oncotarget. 2015;6(8):6406.

33. Hasanain M, Bhattacharjee A, Pandey P, Ashraf R, Singh N, Sharma S, Vishwakarma A, Datta D, Mitra K, Sarkar J. a-Solanine induces ROS-mediated autophagy through activation of endoplasmic reticulum stress and inhibition of Akt/mTOR pathway. Cell Death Dis. 2015;6(8):e1860.

34. Liao C, Zheng K, Li Y, Xu H, Kang Q, Fan L, Hu X, Jin Z, Zeng Y, Kong X. Gypenoside $L$ inhibits autophagic flux and induces cell death in human esophageal cancer cells through endoplasm reticulum stress-mediated Ca2 + release. Oncotarget. 2016;7(30):47387.

35. Krebs J, Agellon LB, Michalak M. Ca2+ homeostasis and endoplasmic reticulum (ER) stress: an integrated view of calcium signaling. Biochem Biophys Res Commun. 2015;460(1):114-21.

36. Yorimitsu T, Nair U, Yang Z, Klionsky DJ. Endoplasmic reticulum stress triggers autophagy. J Biol Chem. 2006;281 (40):30299-304.

37. Dikic I, Elazar Z. Mechanism and medical implications of mammalian autophagy. Nat Rev Mol Cell Biol. 2018;19(6):349-64.

38. Sridharan S, Jain K, Basu A. Regulation of autophagy by kinases. Cancers. 2011;3(2):2630-54.

39. Corcelle E, Nebout M, Bekri S, Gauthier N, Hofman P, Poujeol P, Fénichel P, Mograbi B. Disruption of autophagy at the maturation step by the carcinogen Lindane is associated with the sustained mitogen-activated protein kinase/extracellular signal-regulated kinase activity. Cancer Res. 2006;66(13):6861-70.

40. Kuo H-H, Kakadiya R, Wu Y-C, Su T-L, Lee T-C, Lin Y-W, Yih L-H. Derivatives of 6-cinnamamido-quinoline-4-carboxamide impair lysosome function and induce apoptosis. Oncotarget. 2016;7(25):38078.

41. Yang C, Wu C, Xu D, Wang M, Xia Q. Astragalosidell inhibits autophagic flux and enhance chemosensitivity of cisplatin in human cancer cells. Biomed Pharmacother. 2016;81:166-75.

42. Wen Z-p, Zeng W-j, Chen Y-h, Li H, Wang J-y, Cheng Q, Yu J, Zhou H-H, Liu Z-Z, Xiao J. Knockdown ATG4C inhibits gliomas progression and promotes temozolomide chemosensitivity by suppressing autophagic flux. J Exp Clin Cancer Res. 2019;38(1):298.

43. Zhang $X$, Kumstel S, Jiang K, Meng S, Gong P, Vollmar B, Zechner D. LW6 enhances chemosensitivity to gemcitabine and inhibits autophagic flux in pancreatic cancer. J Adv Res. 2019;20:9-21.

44. Perlmutter DH. Misfolded proteins in the endoplasmic reticulum. Lab Invest. 1999;79(6):623-38.

45. Ruiz A, Matute C, Alberdi E. Intracellular Ca2+ release through ryanodine receptors contributes to AMPA receptor-mediated mitochondrial dysfunction and ER stress in oligodendrocytes. Cell Death Dis. 2010;1 (7):e54.

46. Kim I, Xu W, Reed JC. Cell death and endoplasmic reticulum stress: disease relevance and therapeutic opportunities. Nat Rev Drug Discov. 2008;7(12):1013-30

47. Brown JM, Giaccia AJ. The unique physiology of solid tumors: opportunities (and problems) for cancer therapy. Cancer Res. 1998;58(7):1408-16.

48. Moenner M, Pluquet O, Bouchecareilh M, Chevet E. Integrated endoplasmic reticulum stress responses in cancer. Cancer Res. 2007;67(22):10631-4.

49. Wang W-A, Groenendyk J, Michalak M. Endoplasmic reticulum stress associated responses in cancer. Biochim Biophys Acta. 2014;1843(10):2143-9.
50. Martinon F. Targeting endoplasmic reticulum signaling pathways in cancer. Acta Oncol. 2012;51(7):822-30.

51. Yadav RK, Chae S-W, Kim H-R, Chae HJ. Endoplasmic reticulum stress and cancer. J Cancer Prev. 2014;19(2):75.

52. Kouroku Y, Fujita E, Tanida I, Ueno T, Isoai A, Kumagai H, Ogawa S, Kaufman R, Kominami E, Momoi T. ER stress (PERK/elF2 a phosphorylation) mediates the polyglutamine-induced LC3 conversion, an essential step for autophagy formation. Cell Death Differ. 2007;14(2):230-9.

53. Maiuri MC, Zalckvar E, Kimchi A, Kroemer G. Self-eating and self-killing: crosstalk between autophagy and apoptosis. Nat Rev Mol Cell Biol. 2007;8(9):741-52.

54. Xu L, Liu J-H, Zhang J, Zhang N, Wang Z-H. Blockade of autophagy aggravates endoplasmic reticulum stress and improves paclitaxel cytotoxicity in human cervical cancer cells. Cancer Res Treat. 2015;47(2):313.

55. Huang $K$, Chen Y, Zhang R, Wu Y, Ma Y, Fang X, Shen S. Honokiol induces apoptosis and autophagy via the ROS/ERK $1 / 2$ signaling pathway in human osteosarcoma cells in vitro and in vivo. Cell Death Dis. 2018;9(2):1-17.

56. Bel S, Hooper LV. Secretory autophagy of lysozyme in Paneth cells. Autophagy. 2018;14(4):719-21.

57. Cheng X, Feng H, Wu H, Jin Z, Shen X, Kuang J, Huo Z, Chen X, Gao H, Ye F. Targeting autophagy enhances apatinib-induced apoptosis via endoplasmic reticulum stress for human colorectal cancer. Cancer Lett. 2018;431:105-14

58. Kim J, Kundu M, Viollet B, Guan K-L. AMPK and mTOR regulate autophagy through direct phosphorylation of Ulk1. Nat Cell Biol. 2011;13(2):132-41.

59. Cinà DP, Onay T, Paltoo A, Li C, Maezawa Y, De Arteaga J, Jurisicova A, Quaggin SE. Inhibition of MTOR disrupts autophagic flux in podocytes. J Am Soc Nephrol. 2012;23(3):412-20.

60. Button RW, Vincent JH, Strang CJ, Luo S. Dual PI-3 kinase/mTOR inhibition impairs autophagy flux and induces cell death independent of apoptosis and necroptosis. Oncotarget. 2016;7(5):5157.

61. Mebratu Y, Tesfaigzi Y. How ERK1/2 activation controls cell proliferation and cell death: is subcellular localization the answer? Cell cycle 2009;8(8):1168-75.

62. Cagnol S, Chambard JC. ERK and cell death: mechanisms of ERKprolifed cell death-apoptosis, autophagy and senescence. FEBS J. 2010;277(1):2-21.

63. Zhao Y, Li X, Ma K, Yang J, Zhou J, Fu W, Wei F, Wang L, Zhu W-G. The axis of MAPK1/3-XBP1u-FOXO1 controls autophagic dynamics in cancer cells. Autophagy. 2013;9(5):794-6.

64. He W, Zhang A, Qi L, Na C, Jiang R, Fan Z, Chen J. FOXO1, a potential therapeutic target, regulates autophagic flux, oxidative stress, mitochondrial dysfunction, and apoptosis in human cholangiocarcinoma QBC939 cells. Cell Physiol Biochem. 2018;45(4):1506-14.

\section{Publisher's Note}

Springer Nature remains neutral with regard to jurisdictional claims in published maps and institutional affiliations.

Ready to submit your research? Choose BMC and benefit from

- fast, convenient online submission

- thorough peer review by experienced researchers in your field

- rapid publication on acceptance

- support for research data, including large and complex data types

- gold Open Access which fosters wider collaboration and increased citations

- maximum visibility for your research: over $100 \mathrm{M}$ website views per year

At BMC, research is always in progress.

Learn more biomedcentral.com/submissions 